\title{
Anatomical Demonstration of the Cognitive Ability of the Juvenile African Giant Pouched Rat (Cricetomys gambianus - Waterhouse, 1840)
}

\author{
*Ibe, C. S., Ezeifeka, A. C. \& Ikpegbu, E. \\ Department of Veterinary Anatomy, Michael Okpara University of Agriculture, Umudike Abia State Nigeria
}

*Corresponding author: ibe.chikera@ mouau.edu.ng; 08032882105

\begin{abstract}
Cognitive ability in animals is determined using indices such as Encephalisation Quotient (EQ), relative brain weight, glial quotient and neuronal index. In this study, the cognitive ability of the juvenile African giant pouched rat was determined using the EQ and relative brain weight. Brain samples were routinely extracted from thirty-two juvenile (16 males and 16 females, respectively) rats and fixed in freshly prepared $10 \%$ buffered formalin. The nose-rump length, tail length absolute and relative brain weights were determined according to standard technique while the EQ was computed using the Martin's formula. Structural observations revealed a diamond shaped lissencephalic cerebral cortex with the caudal colliculi exposed from the dorsal transverse fissure of the intact brain. An EQ of 0.75 was deduced for the juvenile African giant pouched rat from the study. Sexual dimorphic analysis revealed mean relative brain weight of $6.64 \pm 0.30$ and $6.90 \pm 0.22$ and mean EQ of $0.71 \pm$ 0.06 and $0.78 \pm 0.02$, for the male and female juveniles respectively. The mean differences between the males and females were not statistically significant $(\mathrm{P}>0.05)$. However, there was a significant negative correlation between nose-rump length and EQ (R2 = 0.66; $\mathrm{p}<0.05)$, nose-rump length and relative brain length $(\mathrm{r} 2=0.49 ; \mathrm{p}<0.05)$ as well as nose-rump length and relative weight of cerebrum $(\mathrm{R} 2=0.61 ; \mathrm{p}<0.05)$. The results were compared with that of other age groups of the same rodent and other juvenile rodents. It was concluded that the juvenile African giant pouched rat may be a better choice for memory and cognitive studies than the adult
\end{abstract}

Keywords: African giant pouched rat, cognition, encephalisation quotient (EQ), relative brain weight.

\section{INTRODUCTION}

The African giant pouched rat is a wild rodent. However, it has gained relevance in research due to its acute olfactory sense, thus, it is currently domesticated for research purposes. The domestication of this wild rodent calls for a good understanding of their biology. The brain of the adult African giant pouched rat has been extensively studied (Nzalak et al., 2008; Ibe et al., 2010; Olude et al., 2014), but similar studies on the juveniles is lacking in available literature.

Cognitive brain markers include relative size of the brain, cortical gray matter thickness, Encephalisation Quotient (EQ) and cortical neurone number; however, EQ and cortical neurone number are more reliable markers (Roth \& Dicke, 2005; Herculano-Houzel, 2007; Narr et al., 2007). Herculano-Houzel (2007) observed that more encephalised rodents have higher cortical neurone numbers than expected for their body size and proposed that the excess neurones may be responsible for the improved associative functions. The EQ is a useful measure which provides the information of how much bigger or smaller an animal's brain is, after the effect of body size has been corrected. It was first proposed as a useful parameter based on the observation that some animals, humans foremost, seem to have larger brains than expected for their body size (Jerison, 1977). Cognitive ability has been recorded in some rodents such as mouse, hamster, rat, guinea pig, agouti, and capybara (Herculano-Houzel et al., 2006), African giant pouched rat (Byanet \& Dzenda, 2014) and African grasscutter (Ibe et al., 2017). However, in most of the above mentioned animals, the study involved demonstration of the cognitive ability of the adult. 
Furthermore, recent studies (Olude et al., 2014; Ibe et al., 2017) have shown that the best learning ability resides in the juveniles than in the adult animals, hence juveniles should be preferred for experimental research centered on cognition. Unfortunately, the cognitive ability of juvenile African giant pouched rat has not been established.

This present research will increase available information on rodent neuroanatomy. It will also serve as a template for further neurological studies with respect to cognitive ability in rodents and a reference point in animal behavioral training. Specific objectives of the study included to study the gross morphology and morphometry of the brain of the juvenile African giant pouched rat, establish the EQ and relative brain weight as indices of cognition and identify any sexual dimorphism in the gross morphology and morphometry of the rodent's brain.

\section{MATERIALS AND METHODS}

\section{RESEARCH ANIMALS AND THEIR MANAGEMENT}

Thirty-two (32) juvenile African giant pouch rats (Cricetomys gambianus) (16 males and 16 females) purchased from hunters in Okigwe, Imo state, Nigeria and environs were used. They were classified as juveniles based on method of Asibey \& Addo (2000) using two criteria, namely confirmation of only two sets of cheek teeth comprising 1 set of premolar and 1 set of molar and body weight of less than $800 \mathrm{~g}$. They were transported in metal cages to the Embryology/Histology Laboratory of College of Veterinary Medicine, Michael Okpara University of Agriculture Umudike. They were acclimatized for 2 weeks, during which they were fed with formulated pelleted feed and water ad libitum. During this period, they were also clinically examined and ascertained to be healthy for the research

The experimental procedure got the approval of the Research Ethics Committee, College of Veterinary Medicine, Michael Okpara University of Agriculture Umudike, Nigeria. The ethical approval number assigned to the work is: MOUAU/CVM/REC/202119.

\section{BRAIN EXTRACTION}

The animals were sedated by using mild inhalation chloroform and immediately, the life weights were taken using weighing balance (Citizen Scales (1) PVT Ltd. South Patel Nagar, New Delhi, sensitivity: 10.00 g). The nose-rump and tail lengths were also obtained with a centimeter measuring ruler and the anogenital distance was obtained using the Vernier caliper. Thereafter, each animal was placed on a dorsal recumbency on a dissection table, and perfused with $10 \%$ paraformaldehyde fixative, through the left ventricle, using a modification of the method of Gage et al.
(2012). Immediately after the perfusion fixation, the head was separated from the rest of the body at the occipitoatlantial joint, using a pair of scissors and knife; the weight of the head was extracted.

Each skull containing the brain was obtained after skinning and stripping off all the facial muscles; then, craniotomy preceded the brain extraction. Specifically, brain extraction was performed in a caudo-rostral and dorso-ventral direction, using scalpel blades, thumb forceps, rongeur and a pair of scissors as described by Ibe et al. (2017). The meninges and underlying blood vessels were gently removed to expose the intact brain.

\section{MORPHOLOGICAL AND MORPHOMETRIC BRAIN STUDIES}

The structural characteristics of the different components of the brain were examined with the naked eye. These included their shape, size, surfaces, borders and angles. The presence or absence of sulci, fissures or prominences was also evaluated. Finally, the projections of the different cranial nerves from the medulla oblongata were observed with both the naked eye and with the aid of a hand lens. Definitions of gross anatomical structures were based on standard information on rodent anatomy. Nomina Anatomica Veterinaria (2012) was used for the nomenclature.

The brain mass was obtained using a weighing balance (Mettler instrument AG., Greifensee, Switzerland) with a sensitivity of $0.01 \mathrm{~g}$ ) while the brain length and width were traced on rope and values obtained from a centimeter ruler. The brain length was measured as the rostro-caudal extent from the tip of the olfactory bulb to the pyramidal decussation of the medulla oblongata, at the level of the foramen magnum, while the brain width was measured as the widest horizontal extent of the brain. The relative brain weight was calculated as a percentage of the live weight occupied by the brain weight. Similarly, the relative brain length was calculated as the percentage of the nose-rump length occupied by the brain length. Thereafter, the brain samples were dissected separating the 3 parts namely cerebrum, cerebellum, and brain stem and the mass, length and width of each of them were obtained according to standard technique. Encephalisation quotient was calculated using the formula of Martin (1984) for the expected brain mass as shown below:

$\mathrm{EQ}=\underline{\text { Mbrain }}$

$0.059 \mathrm{M}_{\text {body }}{ }^{0.76}$ (Martin's formula for expected brain mass)

Where $\mathrm{EQ}=$ Encephalisation quotient; Mbrain = Absolute brain weight $(\mathrm{g})$; Mbody = Body weight $(\mathrm{g})$. 


\section{DATA ANALYSIS}

The data obtained were expressed as mean \pm SEM (standard error of mean), and presented on tables and graphs. Data of weight and dimensions of the male and female brain samples were subjected to one-way analysis of variance, followed by Tukey's post-hoc test to determine significance of the mean. Association between nose-rump length and weight/dimension of the brain were determined using Pearson's coefficient of correlation, at $95 \%$ confidence interval. Values of $p \leq 0.05$ were considered significant. GraphPad Prism version 4 (GraphPad Software Inc., San Diego, CA) for Windows 10 was used for the statistical analysis.

\section{RESULTS}

\section{MORPHOLOGIC STUDY}

On the dorsal view of the intact brain of the juvenile African giant pouched rat (Fig. 1), the cerebral cortex was distinctly divided by a longitudinal fissure and separated from the cerebellum by a transverse fissure. The cerebral cortex was large, diamond-shaped, narrow rostrally and wider caudally. It was devoid of prominent gyri and sulci; the bulging of the frontal lobe was evident. The olfactory bulbs were also very prominent and visible from the dorsal view. They were roughly pyramidal in shape. The cerebellum was very distinct and secondary to the cerebrum in size. The cerebellar cortex was highly coiled with a distinct unpaired vermis; the paired flocculus, but the lateral accessory parts, the paraflocculi, were absent in all brain samples.

The most medial part of the medulla oblongata was the dorsal median sulcus, which was faintly visible. The dorsal median sulcus continued on the floor of the fourth ventricle, where it was more visible than in the closed part of the medulla oblongata.

On a ventral view (Fig. 2), the large olfactory bulbs and tracts relaying impulses to the olfactory cortex were evident. The olfactory nerve fibres, which were rostral to the bulbs, could not be accessed due to their position in the cribriform plate of the ethmoid bones. The paired optic nerves (CN II) united at the optic chiasma and gave off optic tracts that ran on the rostral boarder of the tuber cinerium. They were the fourth largest cranial nerve after the trigeminal nerve (CN V), facial nerve (CN VII) and olfactory nerve (CN I) in all of the dissected animals. The oculomotor nerve (CN III) and trochlear nerve (CN IV) were lost during dissection due to their minute size. The mammillary bodies were relatively

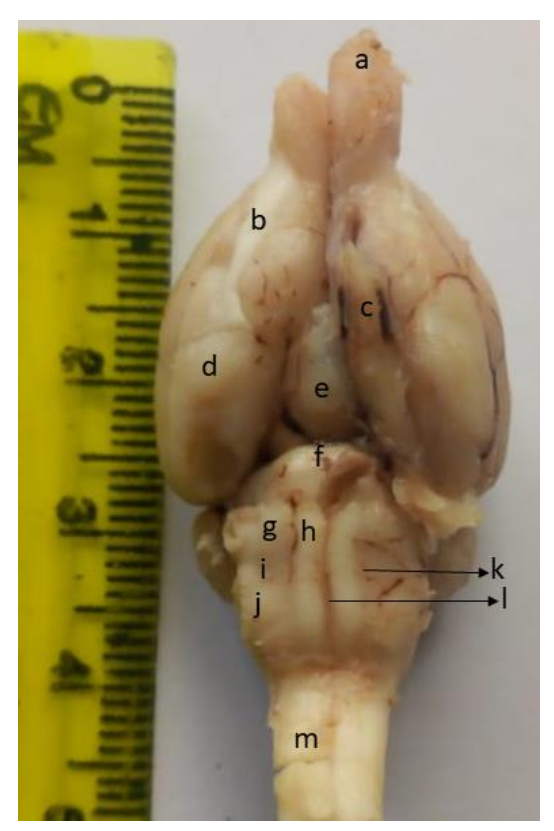

Figure: II: Ventral View of the Brain of the Juvenile African Giant Pouched Rat. a: olfactory bulb; b: olfactory tract; c: trigeminal nerve; d: piriform lobe; e: mammillary body; f: pons; g: trapezoid body; h: pyramid; i: post olivary sulcus; $\mathrm{j}$ : 
TABLE 1: Morphometric Values of the Body and Whole Brain of Juvenile African Giant Pouched Rat (mean \pm SEM)

\begin{tabular}{llll}
\hline Parameter & Minimum & Maximum & Mean \pm SEM \\
Live Weight (g) & 600 & 746 & $728 \pm 18.90$ \\
Nose-Rump Length (mm) & 280.00 & 360.00 & $302.00 \pm 0.70$ \\
Tail Length (mm) & 320.00 & 400.00 & $355.40 \pm 0.69$ \\
Ano-Genital Distance (mm) & 25.00 & 65.00 & $40.10 \pm 0.39$ \\
Head Weight (g) & 65.70 & 92.26 & $75.53 \pm 2.34$ \\
Absolute Brain Weight (g) & 5.60 & 7.50 & $6.77 \pm 0.18$ \\
Relative Brain Weight (\%) & 0.76 & 0.98 & $0.93 \pm 0.69$ \\
Absolute Brain Length (mm) & 35.00 & 40.00 & $38.00 \pm 0.06$ \\
Relative Brain Length (\%) & 11.99 & 13.02 & $12.58 \pm 0.24$ \\
Brain Width (mm) & 27.00 & 40.00 & $32.60 \pm 0.11$ \\
EQ & 0.57 & 0.85 & $0.75 \pm 0.03$ \\
\hline
\end{tabular}

immediately caudal to it. Caudally, the medulla oblongata could be differentiated from the spinal cord by the prominent transverse depression caudal to the pyramidal decussation at the level of the foramen magnum.

\section{MORPHOMETRIC STUDY}

The Morphometric values of the body and whole brain of the juvenile African giant pouched rat was represented on Table 1, while the morphometric values for the brain parts was represented on Table 2 . The mean tail length of the male and female juveniles was $35.08 \pm 0.59 \mathrm{~mm}$ and $36.00 \pm 1.30 \mathrm{~mm}$ respectively. The difference between the male and female juveniles tail length was not statistically significant $(\mathrm{P}>0.05)$. The mean ano-genital distance of the male and female was $43.20 \pm 0.76 \mathrm{~mm}$ and $37.00 \pm 0.26 \mathrm{~mm}$, respectively. The difference was statistically significant $(\mathrm{P}<$ 0.05). Furthermore, the mean head weight was $74.48 \pm 4.68 \mathrm{~g}$ and $76.58 \pm 1.50 \mathrm{~g}$ for the male and female animals, respectively. The difference was not significant $(\mathrm{P}>0.05)$. Furthermore, there was no significant difference $(P>0.05)$ in the body and brain parameters of the male and female juveniles, as presented on Tables 3 and 4 below.

There was a significant negative correlation between noserump length and EQ $\left(\mathrm{R}^{2}=0.66 ; \mathrm{p}<0.05\right)$. The correlation result was subjected to regression analyses and a regression formula was deduced on a graph (Figure 1), as stated below post-olivary sulcus. The rootlets of nerves that emerged from these sulci were lost during dissection, thus, could not be evaluated. Rostrally, the pyramids ended at the pontomedullary junction. The basal pons served as the landmark for identifying the pontomedullary junction. The transverse bundle of fibres that made up the trapezoid body was parallel to the pons and was
Table II: Morphometric Values of the Brain Parts in the Juvenile African Giant Pouched Rat (mean \pm SEM)

\begin{tabular}{|c|c|c|c|c|}
\hline & Parameter & Minimum & Maximum & Mean \pm SEM \\
\hline \multirow[t]{4}{*}{ Cerebrum } & Absolute Weight (g) & 2.70 & 4.00 & $3.510 \pm 0.12$ \\
\hline & Relative weight (\%) & 48.21 & 55.39 & $51.79 \pm 0.72$ \\
\hline & Absolute Length (mm) & 25.00 & 35.00 & $31.00 \pm 0.12$ \\
\hline & Relative Length (\%) & 71.42 & 94.59 & $81.48 \pm 2.72$ \\
\hline \multirow[t]{4}{*}{ Cerebellum } & Absolute Weight (g) & 0.69 & 1.00 & $0.86 \pm 0.03$ \\
\hline & Relative weight (\%) & 10.00 & 14.29 & $12.70 \pm 0.37$ \\
\hline & Absolute Length (mm) & 10.00 & 18.00 & $14.80 \pm 0.07$ \\
\hline & Relative Length (\%) & 25.64 & 51.43 & $39.14 \pm 2.09$ \\
\hline \multirow[t]{4}{*}{ Brainstem } & Absolute Weight (g) & 1.10 & 1.60 & $1.39 \pm 0.05$ \\
\hline & Relative weight (\%) & 16.92 & 26.79 & $20.69 \pm 1.01$ \\
\hline & Absolute Length (mm) & 20.00 & 30.00 & $25.30 \pm 0.09$ \\
\hline & Relative Length (\%) & 51.28 & 81.08 & $66.86 \pm 2.94$ \\
\hline
\end{tabular}


Table III: Sexual Dimorphism in the Body and Brain Morphometry of the Juvenile African Giant Pouched Rat (mean \pm SEM)

\begin{tabular}{|c|c|c|c|c|c|c|c|}
\hline Sex & $\begin{array}{c}\text { Live Weight } \\
\text { (g) }\end{array}$ & $\begin{array}{c}\text { Absolute } \\
\text { Brain } \\
\text { Weight (g) }\end{array}$ & $\begin{array}{c}\text { Relative } \\
\text { Brain } \\
\text { Weight } \\
(\%) \\
\end{array}$ & $\begin{array}{c}\text { Nose-Rump } \\
\text { Length (mm) }\end{array}$ & $\begin{array}{c}\text { Absolute } \\
\text { Brain } \\
\text { Length } \\
(\mathbf{m m}) \\
\end{array}$ & $\begin{array}{c}\text { Relative } \\
\text { Brain } \\
\text { Length }(\%) \\
\end{array}$ & EQ \\
\hline Male $(n=16)$ & $720.00 \pm 120.00$ & $6.64 \pm 0.30$ & $0.93 \pm 0.09$ & $304.00 \pm 14.70$ & $38.00 \pm 1.20$ & $12.58 \pm 0.57$ & $0.71 \pm 0.06$ \\
\hline Female $(n=16)$ & $632.00 \pm 32.00^{\mathrm{ns}}$ & $6.90 \pm 0.22^{\mathrm{ns}}$ & $1.05 \pm 0.03^{\text {ns }}$ & $300 \pm 16.90^{\mathrm{ns}}$ & $38.00 \pm 0.49^{\mathrm{ns}}$ & $12.67 \pm 0.15^{\mathrm{ns}}$ & $0.78 \pm 0.08^{\mathrm{ns}}$ \\
\hline
\end{tabular}

\begin{tabular}{cccccccc}
\hline \multicolumn{1}{c}{ Table IV: Morphometric Values of the Brain Divisions in the Juvenile African Giant Pouched Rat (mean \pm SEM) } \\
\hline & \multicolumn{2}{c}{ Cerebrum } & \multicolumn{2}{c}{ Cerebellum } & \multicolumn{2}{c}{ Brainstem } \\
Relative & $\begin{array}{c}\text { Relative } \\
\text { weight }\end{array}$ & length & $\begin{array}{c}\text { Relative } \\
\text { weight }\end{array}$ & $\begin{array}{c}\text { Relative } \\
\text { length }\end{array}$ & $\begin{array}{c}\text { Relative } \\
\text { weight }\end{array}$ & $\begin{array}{c}\text { Relative } \\
\text { length }\end{array}$ \\
\hline Male $(\mathbf{n}=\mathbf{1 6})$ & $50.82 \pm 0.89$ & $82.43 \pm 5.08$ & $12.35 \pm 0.66$ & $41.86 \pm 2.82$ & $21.95 \pm 1.67$ & $68.79 \pm 3.27$ \\
Female $(\mathbf{n}=\mathbf{1 6})$ & $52.76 \pm 1.03^{\mathrm{ns}}$ & $86.25 \pm 3.71^{\mathrm{ns}}$ & $13.06 \pm 0.35^{\mathrm{ns}}$ & $36.42 \pm 2.83^{\mathrm{ns}}$ & $19.42 \pm 1.08^{\mathrm{ns}}$ & $64.93 \pm 5.13^{\mathrm{ns}}$ \\
\hline
\end{tabular}

$y=-0.038 x+1.906$

There was a significant negative correlation between noserump length and relative brain length $\left(R^{2}=0.49 ; p<0.05\right)$. The correlation result was subjected to regression analyses and a regression formula was deduced on a graph (Figure 2), as stated below

$\mathrm{y}=-0.278 \mathrm{x}+21.04$

\section{DISCUSSION}

Structural observations revealed a diamond shaped lissencephalic cerebral cortex with the caudal colliculi exposed from the cerebral transverse fissure of the intact brain. Similar observation was reported in the adult African giant pouched rat by Ibe et al. (2014). Also, lissencephalic brain has been reported in some rodents of the class sciuromorpha and myomorpha by Pilleri et al. (1984) and in hystricomorpha by Dozo et al. (2004). Conversely, large rodents such as beaver and capybara have been observed to be gyrencephalic (Sereno \& Tootell, 2005) while some small sized primates, such as the marmoset monkey are lissencephalic (Garcı'a-Moreno et al., 2012). The exposure of the caudal colliculi emphasizes its large size relative to the rostral colliculi, an observation that has been linked to the better auditory than visual ability in the African giant pouched rat (Ibe et al., 2010; Ibe et al., 2014). The disposition of the colliculi varies in the African grasscutter (Ibe et al., 2020), Wistar rat (Suckow et al., 2006) and guinea pigs (Potter \& Brueck, 1958).

The relative brain weight and EQ of the juvenile African giant pouched rats were adopted in the present study to determine the cognitive ability of this age group. The value of $0.93 \%$ obtained as the relative brain weight of juvenile African giant pouched rat from the present study is comparable to the value obtained from the same age group of the rodent by Olude et al. (2014). The value is higher than the value of $0.60 \%$ recorded for the adult African giant pouched rat by Ibe et al. (2010). Similarly, the EQ recorded for the juvenile African giant pouched rat from the present study, which is 0.75 , is higher than the value of 0.19 recorded for adult African giant pouched rats by Byanet \& Dzenda (2014). These findings are suggestive of higher cognitive ability in the juvenile African giant pouched rat than in their adult counterpart. Earlier study on neuronal plasticity in the African giant pouched rat by Olude et al. (2014) pointed better cognition in the juveniles and proffered their preferred use to the adults in experimental studies involving memory and cognition. Neuronal loss due to apoptosis may be one of the reasons for low EQ in adult African giant pouched rats compared to the juveniles. The juvenile African grasscutter may have a better cognitive ability than juvenile African giant pouched rat, as the value of relative brain weight (2.49\%) and EQ (1.62) recorded for the juvenile African grasscutter by Ibe et al. (2017) are respectively higher than the values obtained in the present study.

The result of sexual dimorphism in this study showed that the male juvenile weighed more than the female, though the difference in weight was not statistically significant. Studies on the adult African giant pouched rat by Henwood (1985), Nowak (1999) and Ibe et al. (2010) showed that the male is significantly heavier than the female. Therefore, it can be deduced from these studies that the male African giant 
Figure III. Negative linear relationship between noserump length and EQ of juvenile African giant pouched rats

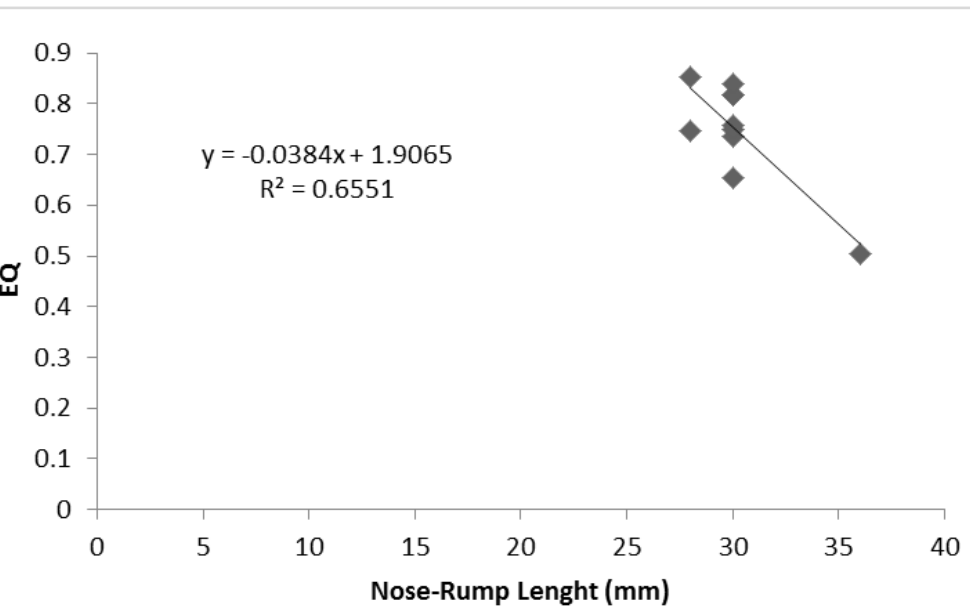

Nose-Rump Lenght ( $\mathrm{mm})$

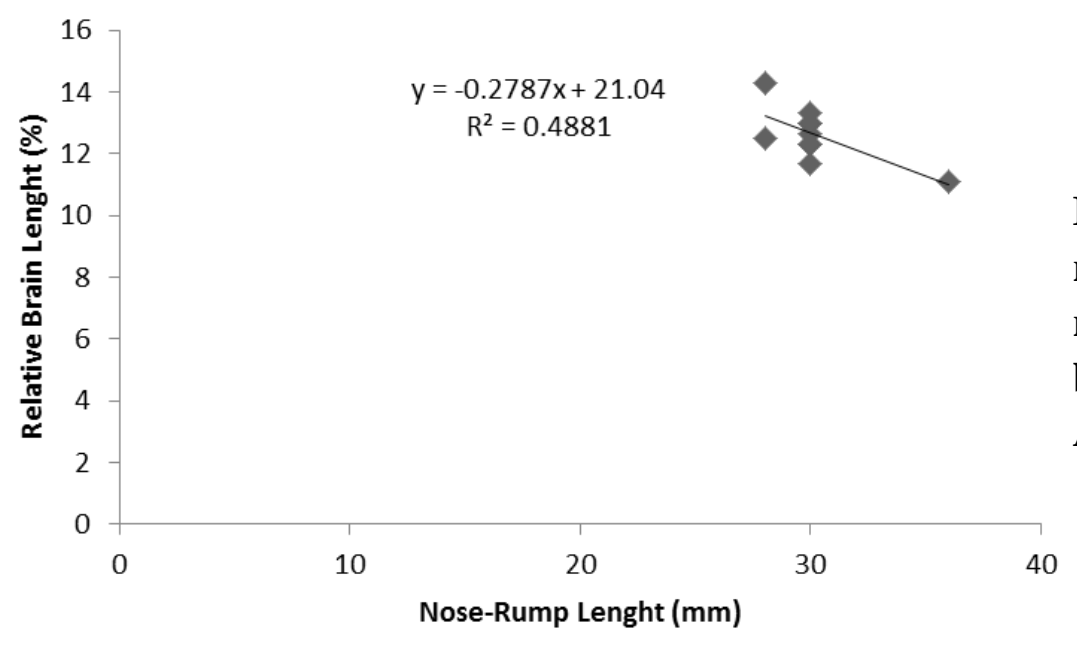

Figure IV: Negative linear relationship between noserump length and relative brain length of juvenile African giant pouched rats.

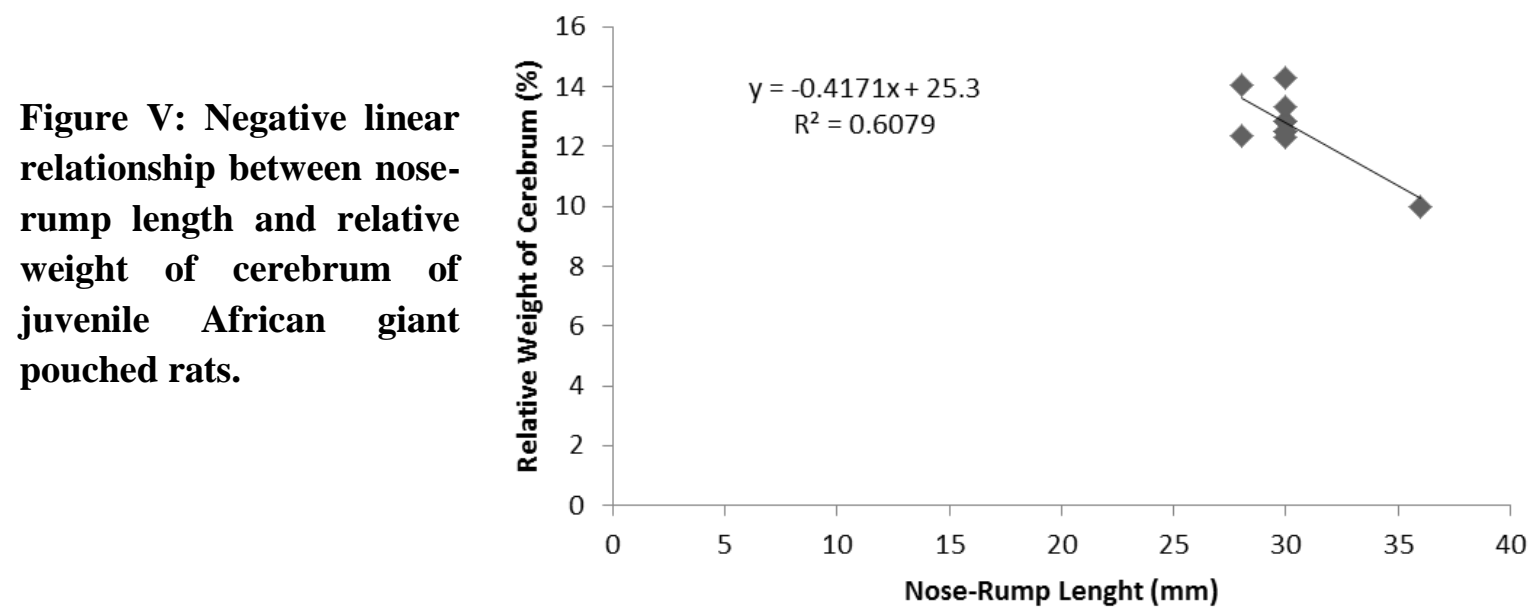

pouched rat weighs more than the female, although the difference in body weight becomes significant with advancement in age. There was a significant correlation between nose-rump length and EQ in the present study. The regression formula deduced can be used to estimate the EQ of live juvenile African giant pouched rat from their noserump length. Similarly, the significant correlation between nose-rump length and relative cerebrum weight obtained in the present study permits an estimation of the relative weight of the cerebrum of live juvenile African giant pouched rats, while the relative brain length can also be estimated from the regression formula deduced from the significant negative correlation of the relative brain length and the nose-rump length. 


\section{CONCLUSION}

The present research has established the EQ of juvenile African giant pouched rat, and compared it with the adult, thus, reiterating inference from previous studies that conferred better cognitive ability on juvenile than adult rodents. This study has also shown that the juvenile African giant pouched rat is lissencephalic. Regression formulae applicable for the estimation of $\mathrm{EQ}$, relative weight of cerebrum and relative brain length in live juvenile African giant pouched rats have also been deduced. These findings will serve as reference for future anatomical and behavioural studies involving the African giant pouched rat.

\section{CONFLICT OF INTEREST}

The authors hereby declare that there is no conflict of interest with regards to this publication.

\section{REFERENCES}

Asibey, E. O. A. \& Addo, P. G. (2000). The grasscutter, a promising animal for meat production. In Turnham, D.: African Perspectives. Practices and Policies Supporting Sustainable Development. Scandinavian Seminar College, Denmark, in association with Weaver Press, Harare, Zimbabwe, 120 pp.

Byanet, O. \& Dzenda, T. (2014). Quantitative biometry of body and brain in the Grasscutter (Thryonomys swinderianus) and African giant rat (Cricetomys gambianus): encephalisation quotient implication. Research in Neuroscience, 3, 1-6.

Dozo, M.Y., Vucetich, M.G. \& Candela, A.M. (2004). Skull anatomy and neuromorphology of Hypsosteiromys, a colhuehuapian erethizontid rodent from Argentina. Journal of Vertebrate Paleontology, 24, 228-234.

Gage, G. J., Kipke, D. R. \& Shan, W. (2012). Whole animal perfusion fixation for rodents. Journal of Visualized Experiments, 65, e3564.

Garcı'a-Moreno, F., Vasistha, N. A., Trevia, N., Bourne, J. A. \& Molnar, Z. (2012). Compartmentalization of cerebral cortical germinal zones in a lissencephalic primate and gyrencephalic rodent. Cerebral Cortex, 22, 482-492.

Henwood, C. (1985). The Handbook of Rodents in Captivity. Unusual Types. Ian Henry Publications, Hornchurch, pp. 345.

Herculano-Houzel, S. (2007). Encephalization, neuronal excess and neuronal index in rodents. Anatomical Record, 290, 128-1287.

Herculano-Houzel, S., Mota, B. \& Lent, R. (2006). Cellular scaling rules for rodent brains. Proceeding of National Academy of Science U. S. A., 103, 12138-12143.

Ibe, C. S., Onyeanusi, B. I. \& Hambolu, J. O. (2014). Functional morphology of the brain of the African giant pouched rat (Cricetomys gambianus, Waterhouse, 1840). Onderstepoort Journal of Veterinary Research, 81, e1-e7.
Ibe, C. S., Onyeanusi, B. I., Hambolu, J. O. \& Ayo, J.O. (2010). Sexual dimorphism in the whole brain and brainstem morphometry in the African giant pouched rat (Cricetomys gambianus, Waterhouse 1840). Folia Morphologica, 69 (2), 69-74.

Ibe, C. S., Salami \& Wanmi N. (2017). Brain size of the African grasscutter (Thryonomys swinderianus, Termink, 1827) at different postnatal periods. Folia Veterinaria, 61 (4), 5-11.

Ibe, C. S., Ikpegbu, E. \& Ogbonnaya, O. (2020). Gross morphology of the cerebrum and brainstem of the adult African grasscutter (Thryonomys swinderianus Temminck, 1827). Folia Veterinaria, 64 (4), 63-70.

Jerison, H. J. (1977). The theory of encephalisation. Annual New York Academy of Science, 299, 146-160.

Martin, R. D. (1984). Body size, brain size and feeding strategies. In Chivers, D., Wood, B., Bilsborough, A.: Food Acquisition and Processing in Primates. Plenum Press, New York, 73-103.

Narr, K. L., Woods, R. P., Thompson, P. M., Szeszko, P., Robinson, D. \& Dimtcheva, T. (2007). Relationships between IQ and regional cortical gray matter thickness in healthy adults. Cerebral Cortex, 17, 2163-2171.

Nomina Anatomica Veterinaria (2012). International Committee on Veterinary Gross Anatomical Nomenclature, 7th edn., Hannover, Columbia.

Nowak, R. (1999). Walker's mammals of the world. Vol. 2. The John Hopkins University Press, Baltimore and London.

Nzalak, J.O., Byanet, O., Salami, S.O., Umosen, A.D., Maidawa, S.M. \& Ali, M.N. (2008). Comparative morphometric studies of the cerebellum and forebrain of the African Giant rat (Cricetomys gambianus, Waterhouse) and that of grasscutter (Thryonomys swinderianus). Journal of Animal and Veterinary Advances, 7, 1090-1092.

Olude, A. M., Olopade, J. O. \& Ihunwo, A. O. (2014). Adult neurogenesis in the African giant rat (Cricetomys gambianus, Waterhouse). Metabolic Brain Disease, 29, 857-866.

Pilleri, G., Gihr, M. \& Kraus, C. (1984). Cephalization in rodents with particular reference to the Canadian beaver (Castor canadensis). In G. Pilleri (ed.), Investigations on Beavers' Institute of Brain Anatomy, pp. 11-102, University of Berne.

Potter, G. E. \& Brueck, W. L. (1958). Nervous system of guinea pig (Cavia porcellus). Bios, 29, 185-196.

Roth, G. \& Dicke, U. (2005). Evolution of the brain and intelligence. Trends in Cognitive Sciences, 9, 250-257.

Sereno, M. I. \& Tootell, R. B. H. (2005). From monkeys to humans: what do we now know about brain homologies. Current Opinion in Neurobiology, 15, 135-144

Suckow, M. A., Weisbroth, S. H. \& Franklin, C. L. (2006). The Laboratory Rat. Elsevier Academic Press, Oxford UK, 230-439.

Article history: Received: July 25, 2021, Revised: Oct. 13, 2021, Accepted: Nov. 6, 2021 